\title{
Varietal variations of oil and fatty acids in rapeseed mustard
}

\begin{abstract}
The present paper deals with the study of variations of oil and fatty acids in mustard. The oil content of seed samples of different of different mustard varieties has been found to show a wide variation between $30.00 \%$ to $39.00 \%$. PC-5 variety of seed has been found to have the maximum content of oil i.e. $39.26 \%$ The major component of fatty acid Erucic acid is varied $35.00 \%$ to $60.70 \%$.PC-5 variety is at the top with the $60.20 \%$ value of Erucic Acid.
\end{abstract}

Volume 2 Issue 8 - 2017

\author{
Alka Srivastava, Ashok Kumar Srivastava, \\ Rashmi Mohan Mathur, Rachna Prakash, \\ Shashi Agrawal \\ Department of Chemistry DAV (PG) College, India
}

Correspondence: Alka Srivastava, Department of Chemistry DAV (PG) College, India, Email alkashokl4@yahoo.com

Received: February 21, 2017| Published: December 28, 2017

\section{Introduction}

Rapeseed mustard, family cruciferae and genus Brassica, is very important oilseed crop of the world as it is the world's third leading source of vegetable oil. Mustard seed, in India, is widely used as source of edible oil and animal feed. The nutritional value of oil largely depends upon its fatty acid composition The Rapeseed mustard produces industrial oil on account of high erucic acid content. The presence of high erucic acid content in Rapeseed mustard oil valued as oleo chemicals. The high erucic materials being grown in this country have proven agronomic value. The high erucic acid content is equally desirable for the use of mustard oil for technical purposes. In industry the erucic acid is put to several uses. It is used for manufacture of certain chemicals, antifoaming agents, various types of resins, plasticizers and surfactants. Therefore ten varieties were screened for chemical compositions to find out the variability for oil content and fatty acid to select out superior ones for breeding and industrial purposes.

\section{Materials and methods}

10 varieties were collected maintained and grown in bulk by senior breeders under uniform fertility conditions. They were evaluated for agronomic values and promising materials were passed on for biochemical analysis.

Oil content was estimated by Soxhlet extraction using petroleum Ether in cold as a solvent. The solvent was removed and oil was subjected to methylation. The methyl esters were prepared from the oil by Tran's methylation with sodium methoxide methanol reagent as proposed by Luddy. Fatty acid composition is determined by gas liquid chromatography

\section{Results and discussion}

Variety k1 and CSR 8709 occupied second and third rank in respect of Oil content Tables $1 \& 2$. Different fatty acids present in oil indicated wild and significant variability. However the oil appeared to be dominated by erucic acid to the extent of $60.20 \%$, while remaining six fatty acid formed only about $40 \%$ of the glyceride composition of rapeseed mustard oil. Palmatic acid (C16:0) varied significantly from $1.90 \%$ to $3.90 \%$ while stearic acid C18:0 ranged from 1.90-3.90 while stearic acid $\mathrm{C} 18: \mathrm{O}$ ranged from .18 to $2.52 \%$ concentration of linoleic acid C18: 2 is higher than palmatic stearic and oleic acid. Concentration of Eicosenoic acid C20:1 ranges from 2.52 to $7 \%$ Erucic Acid C22:1 the major component of fatty acid of Rapeseed mustard oil exhibited wide and significant variations from $35.00-$ $60.20 \%$.Variety PC-5, K-1 and CSR-8709 were identified to possess higher level of Erucic acid. ${ }^{1-6}$

Table I Results on oil content of different varieties showed wide and significant variations from 29.50-39.26

\begin{tabular}{|c|c|c|c|c|c|c|}
\hline S.No. & Varieties & Oil contents & $\begin{array}{l}\text { Sap value(mg-KOH/g Oil) } \\
\text { (mg KOH/g-Oil) }\end{array}$ & $\begin{array}{l}\text { lodine value } \\
\text { (gl//00g Oil) }\end{array}$ & Total sugar \% & Total amino acid \\
\hline 1 & $T-151$ & 30.1 & 12 & 97 & 4.2 & 1.78 \\
\hline 2 & CSR-8709 & 39 & 14 & 99.2 & 4.15 & 1.9 \\
\hline 3 & Rohini & 35.22 & 10 & 101.2 & 3.61 & 2.25 \\
\hline 4 & Vaibhav & 34.15 & 10.5 & 100 & 3.5 & 2.2 \\
\hline 5 & RLM-619 & 30 & 11.2 & 89.2 & 3.75 & 1.85 \\
\hline 6 & $\mathrm{RH}-30$ & 31.8 & 11.5 & 88 & 4 & 1.05 \\
\hline 7 & PR-8802 & 32.56 & 10.2 & 91.5 & 4.15 & 1.95 \\
\hline 8 & PC-5 & 39.26 & 14.2 & 90.2 & 3.75 & 2.05 \\
\hline 9 & $T-|5|$ & 29.5 & 11 & 80.5 & 3.25 & 2 \\
\hline 10 & $K-I$ & 39.08 & 14 & 89 & 3.5 & 2 \\
\hline
\end{tabular}


Table 2 Variety PC-5 was formed to exhibit maximum oil content $39.26 \%$

\begin{tabular}{lllllllll}
\hline S. No. & Varieties & Palmitic acid & Stearic acid & Ollic acid & Linoleic acid & Linoleic acid & Eicosenoic acid & Erucic acid \\
\hline I & T-I5I & 3.28 & 0.98 & 9 & 30.20 & 4.12 & 3.6 & 40.1 \\
2 & CSR-8709 & 3.12 & 2.52 & 10.2 & 25 & 0.95 & 3.25 & 55.1 \\
3 & Rohini & 4 & 1 & 9.5 & 40.32 & 3 & 4 & 39.25 \\
4 & Vaibhav & 3.9 & 0.9 & 8 & 39 & 8.75 & 3.95 & 35 \\
5 & RLM-6I9 & 3 & 0.85 & 7.95 & 24.25 & 10 & 4.1 & 38.25 \\
6 & RH-30 & 1.95 & 0.7 & 12 & 25.1 & 10.5 & 5.1 & 42 \\
7 & PR-8802 & 1.9 & 0.18 & 11.25 & 28.2 & 9.8 & 7 & 41.29 \\
8 & PC-5 & 3.1 & 2.3 & 12.25 & 14.6 & 2.85 & 3.95 & 60.2 \\
9 & T-I5I & 2.2 & 0.22 & 11.3 & 23 & 10 & 4.5 & 38 \\
10 & K-I & 2.15 & 2.4 & 7.4 & 20.85 & 9.7 & 2.53 & 59.15 \\
\hline
\end{tabular}

\section{Acknowledgements}

None.

\section{Conflict of interest}

The author declares no conflict of interest.

\section{References}

1. Sukar S, Bhattacharya DK. Seed Composition of some new varieties of sesame, toria, yellow sarson and groundnut. J Oil Tech Assn India. 1987;19(1):13-15.

2. Schuster W. Distribution of the fat content of various oil plants, linseed, mustard and soyabeans. J Sci Fd Agric. 1966;20(1):11-55.
3. Srivastava alka, Srivastava Ashok Kumar, Kendurkar PS, et al. Varietal Variation of oil and fatty acids in castor Bean (Ricinus Communis L.). $J$ Chemtraks. 2008;10(1 \& 2):203-206.

4. Mallick SA, Kumari Priya Gupta Mani, Mondal AK, et al. Impact of post anthesis moisture deficit stress on yield and oil quality of mustard Genotype. Indian Journal of Agricultural Biochemistry. 2015;28(1):1117.

5. Srivastava Alka, Mathur Rashmi Mohan, Prakash Rachna, et al. Studies on Ricinus Lipase Enzyme isolated from castor seeds. Oriental Journal of chemistry. 2016;32(2):1235-1247.

6. Agrawal Shashi, Prakash Rachna, Srivastava Alka, et al. Quantitative and Qualitative Analysis of Phytochemical, present in Flower Extract of Hibiscus Rose Sinensis. International Journal of Scientific Research. 2016;5(7):78-79. 